\title{
The Influence of Finishing Operations on the Surface Quality of Injected Parts
}

\author{
Martin Ovsik, Lenka Hylova, Martin Reznicek, Vojtech Senkerik, Michal Stanek \\ Tomas Bata Uniersity in Zlin. TGM 5555, 76001 Zlin. Czech Republic. E-mail: ovsik@utb.cz, hylova@utb.cz, \\ mreznicek@utb.cz,vsenkerik@utb.cz,stanek@utb.cz
}

\begin{abstract}
In the production of plastics tools, due to the high mould price, high demands are placed on cost reduction or shortening mould production times. The price of the injection mould is reflected not only in the price of used injection material but also in the price of its own production.

Mould form cavities were made with different materials and different machining technology (finishing methods). Various polymeric materials were injected into the cavities thus prepared, and the surface quality of the samples was evaluated and compared to the quality of the surface cavities, thereby verifying the copying of the surface of the mould cavity onto the surface of the polymer product. The aim of this article is to determine the impact of technological conditions on the quality of the plastic tool (injection mould) and the future polymer product. In this experiment, they were made by different technological conditions of the shape cavity and their influence on the resulting roughness parameters of tested samples was determined.
\end{abstract}

Keywords: Finishing operations, surface quality, mould, injection part, finishing method

\section{Introduction}

In this study, polycarbonate (PC) is injection moulded into three various moulds produced from different tool materials. $\mathrm{PC}$ is a thermoplastic amorphous polymer owning good optical and mechanical properties such as strength, impact resistance and stiffnes. It is very often used in the automotive, aircraft windshield, architectural glasses, medical apparatus etc [1].

Nowadays, one of the most common technologies of polymer processing is injection moulding. $\mathrm{Xu}, \mathrm{Lu}$, Gao and Zhang investigated numerical and experimental results of injected moulded PC. After numerical simulation and experimental test with different mould temperatures they created the methodology. The yield stress of PC increased with the increasing mould temperature. The fracture energy of PC increased also with increasing mould temperature [2].

Griffiths, Dimov, Brousseau and Hoyle dealt with the interaction between the polymeric melt and the tool surface. They used three polymeric materials, one of these materials was PC. They found no significant relationship between the occurrence of the slip stick effect and the tool surface. The flow length of PC was more susceptible to changes of the process parameters in comparison to polypropylene [3].

The comparison of mould materials aluminium 2000 and AIS 1020 creating a double cavity of the mould during injection moulding of acrylonitrile butadiene styrene Ozcelik, Ozbay and Demirbas studied. When melt temperature and cooling time were high, the values of elasticity modulus and tensile stress at yield were higher in case of aluminium mould in comparison to steel one [4].

The surface segregation during injection moulding of PC and polymethyl methacrylate was studied by Sako, Ito and Yamaguchi. They prepared polymeric blend using twin-screw extruder and subsequently this blend injection moulded. The structure change could be caused by the high shear rate near the mould wall. Surface hardness was positively influenced by the surface localization of polymethyl methacrylate [5-7].

In this study the influence of the surface quality of the cavity of mould on the surface quality of injetion moulded product produced from PC was investigated. Three various material of mould were studied and subsequently compared which material is the best for production of the best surface quality of polycarbonate products [8-10].

\section{Experimental}

This study is concerned with the influence of the surface quality of the mould cavity on the surface quality of the final product manufactured from a polycarbonate. Three materials (1.2343, 1.3505 and 2.0402) and machining methods (turning, grinding and polishing) were used to produce the cavities. Polishing of the cavities was done with three varying head speeds as this parameter affects the quality of the surface. The goal of this study is to consider to what extent does the surface quality of the cavities constructed with varying process parameters, materials and machining methods influence the surface quality of the final product.

\section{- Shape insert of the mould:}

The shape insert of the injection mould has the external dimension $\varnothing 90 \times 12 \mathrm{~mm}$. This insert is screwed on the left side of the injection mould using three screws. In the centre of the insert there is a hole for the flow retainer, which holds the injection moulded sample on the left side of the mould. The sample is ejected using the wiping plate.

The shape insert is produced by turning, its shape is in touch with the polymeric melt, is either polished, turned or grinded under various conditions. Polishing of the insert was done with three varying values of head speed, which influenced the insert's surface quality, therefore the surface quality of the product. The goal of this research is to evaluate the effect of individual machining methods on the surface quality of the finished product as well as the extent to which the surface of the cavity is copied to the surface of the product. 
The shape insert is produced from three various materials such as chrome construction steel 1.3505, chrommolybden tool steels 1.2343 (Table 1.) and 2.0402 (Table 2.). The aim of this research paper is to assess the effect that the material and its heat conduction properties have on the surface quality of the product. Table 1 and 2 display a chemical composition of specified materials used for the construction of the injection mould cavity.

Tab. 1 Chemical composition $(1.3505,1.2343)$ in $\% w t$.

\begin{tabular}{lllllllll}
\hline Material & C & Mn & Si & P max. & S max. & Cr & Mo max. & V \\
\hline $\mathbf{1 . 3 5 0 5}$ & $0.93-1.05$ & $0.25-0.45$ & $0.15-0.35$ & 0.025 & 0.015 & $1.4-1.6$ & 0.1 & \\
$\mathbf{1 . 2 3 4 3}$ & $0.33-0.41$ & $0.25-0.5$ & $0.8-1.2$ & 0.03 & 0.02 & $4.8-5.5$ & $1.1-1.5$ & $0.3-0.5$
\end{tabular}

Tab. 2 Chemical composition (2.0402) in \%wt.

\begin{tabular}{|c|c|c|c|c|c|c|c|}
\hline Material & $\mathrm{Cu}$ & Zn & $\mathbf{P b}$ & Al & $\mathrm{Fe}$ & $\mathrm{Ni}$ & Sn \\
\hline 2.0402 & $57-59$ & & $2.5-3.5$ & up to 0.05 & up to 0.3 & up to 0.3 & up to 0.3 \\
\hline
\end{tabular}

\section{- Injection moulding parameters:}

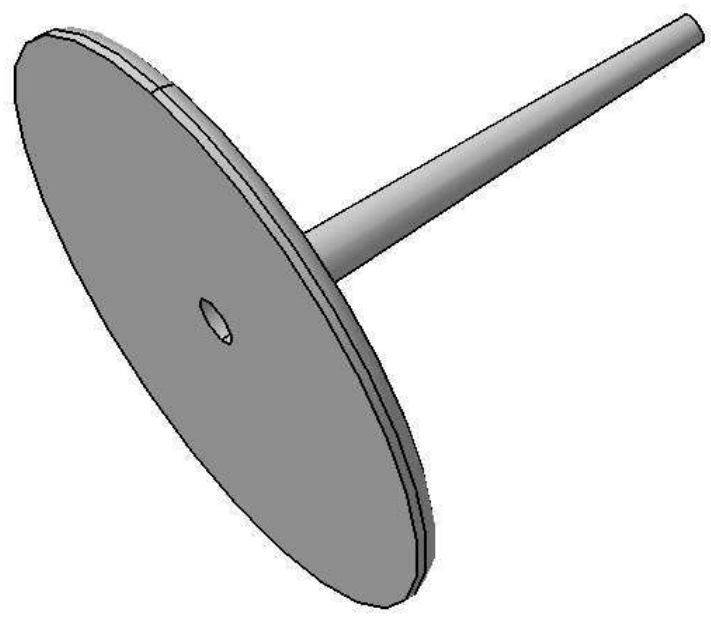

Fig. 1 Tested Sample-PC

Tested Polycarbonate ALTECH PC-HT A 1000/500 by company LBIS PLASTIC GmbH was used as a tested material. Before granulate could be injection moulded, it had to be treated in a Thermolift 100-2 dryer manufactured by Arburg, this was done in compliance with the manufacturer recommendation. Temperature of this process was $120^{\circ} \mathrm{C}$ and it lasted for 4 hours. Afterwards, the treated material was injected in the injection moulding machine ARBURG 470H Allrounder made by Arburg (shown in figure 2). Table 1 provides parameters of the injection moulding process, which were set according to the material sheet of the tested polycarbonate. The main dimension of the sample is $\varnothing 62 \mathrm{~mm} \times 3 \mathrm{~mm}$ (Figure 1).

Tab. 1 Injection moulding parameters

\begin{tabular}{lcl}
\hline Material: & Unit: & PC- HT \\
\hline T1- nozzle & ${ }^{\circ} \mathrm{C}$ & 315 \\
T2 & ${ }^{\circ} \mathrm{C}$ & 320 \\
T3 & ${ }^{\circ} \mathrm{C}$ & 315 \\
T4 & ${ }^{\circ} \mathrm{C}$ & 310 \\
T5 & ${ }^{\circ} \mathrm{C}$ & 305 \\
T6 - hopper & ${ }^{\circ} \mathrm{C}$ & 70 \\
Dosing path & $\mathrm{mm}$ & 14 \\
Injection velocity & $\mathrm{mm} / \mathrm{s}$ & 60 \\
Injection pressure & $\mathrm{MPa}$ & 60 \\
Holding pressure & $\mathrm{MPa}$ & 30 \\
Holding time & $\mathrm{s}$ & 10 \\
Cooling time & $\mathrm{s}$ & 15 \\
\hline
\end{tabular}

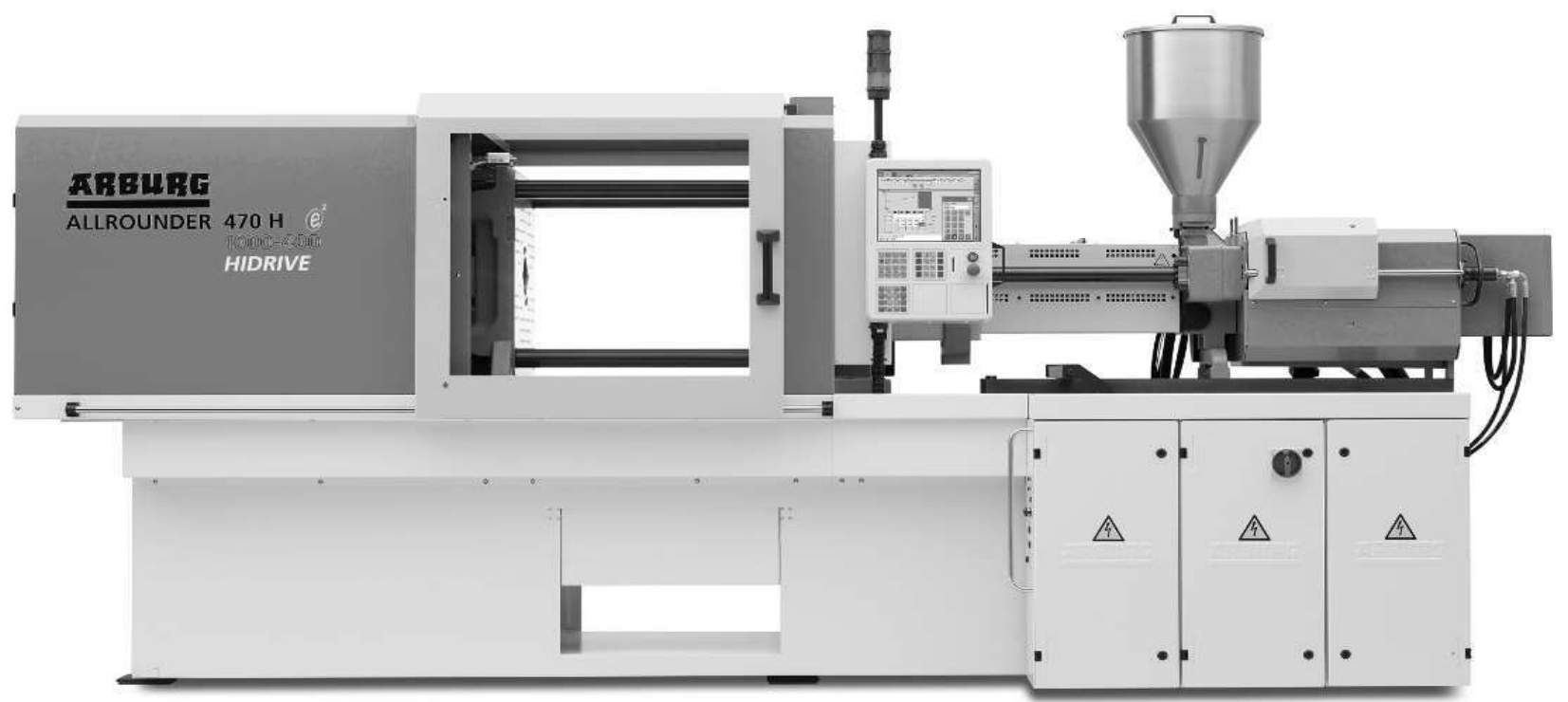

Fig. 2 Injection machine - Arburg Allrounder $470 \mathrm{H}$ 


\section{Surface quality:}

In this experiment, the surface quality from the point of surface roughness was measured using roughness parameters $\mathrm{Ra}$ and $\mathrm{Rz}$ (Figure 3).

$\mathrm{Ra}$ is the arithmetic average of the absolute values of the roughness profile ordinates. The average roughness is the area between the roughness profile and its mean line, or the integral of the absolute value of the roughness profile height over the evaluation length.

$\mathrm{Rz}$ is the arithmetic mean value of the single roughness depths of consecutive sampling lengths. $Z$ is the sum of the height of the highest peaks and the lowest valley depth within a sampling length.

The largest part of measurement of the surface roughness of the shape cavities and polymeric products was measured using 2D contact profilometer Form Talysurf 50.

The one file measurement was always done at ten samples, where three measurements at each sample were done. The basic length of the roughness measurement was determined on $0.8 \mathrm{~mm}$ and in the whole evaluated length it was considered totally five times. The evaluated length was $4 \mathrm{~mm}$. After cancelling of the shape and waviness, the Gauss's filter was used.
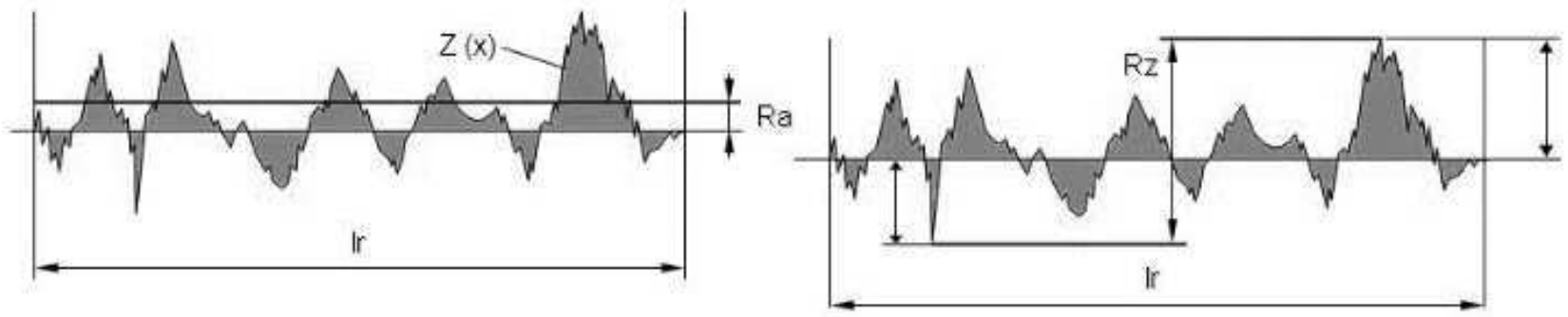

Fig. 3 Surface Quality - Ra, $R z$

\section{Result and Discussion}

In this experiment, the surface quality of products manufactured with varying materials, machining methods and process parameters was measured and subsequently the results were compared with each other.

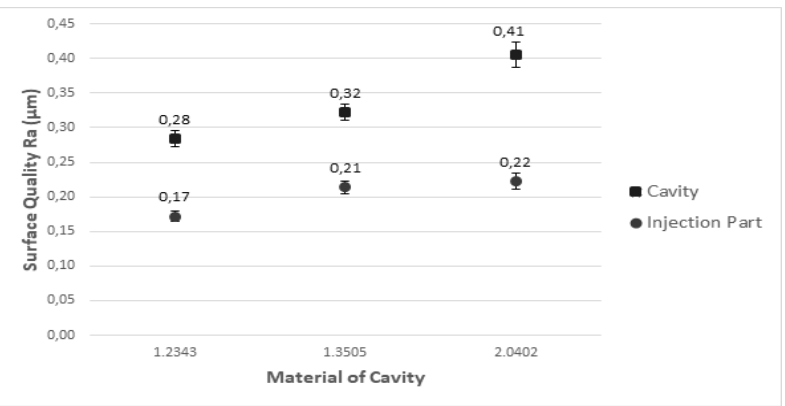

Fig. 4 Surface Quality Ra vs. Material of Cavity

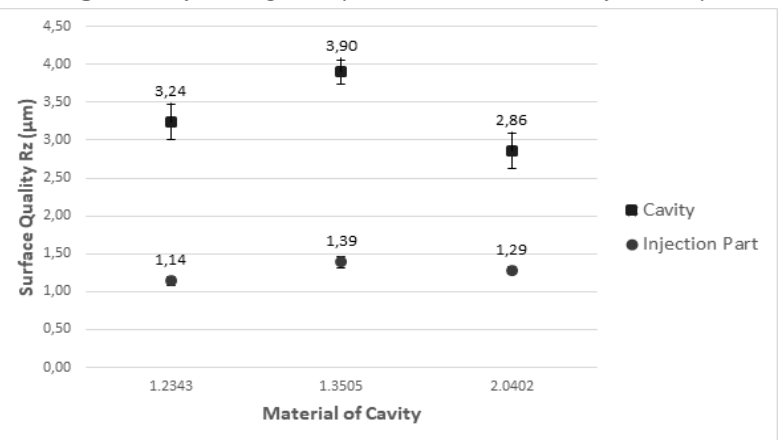

Fig. 5 Surface Quality Rz vs. Material of Cavity

Figure 4 and Figure 5 shows how deeply the surface quality ( $\mathrm{Ra}$ and $\mathrm{Rz}$ ) of the mould is copied on the surface quality of the product using three various mould cavities. The mould cavity was produced by grinding under predetermined conditions (velocity $7 \mathrm{~m} / \mathrm{min}$, depth of cut 0.005 $\mathrm{mm}$ ). At the shape insert produced from material 1.2343 the surface quality Ra was $0.28 \mu \mathrm{m}$ (Rz was $3.24 \mu \mathrm{m})$. At the polymeric product, which was injected into this insert the surface quality Ra was $0.17 \mu \mathrm{m}(\mathrm{Rz}$ was $1.14 \mu \mathrm{m})$. The difference between the insert and the product is $65 \%$ $\mathrm{Ra}(184 \% \mathrm{Rz})$. At the insert 1.3505 the similar tendencies were found out. The surface quality of the product was 52 $\% \operatorname{Ra}(181 \% \mathrm{Rz})$ lower than the surface of the shape insert. At the insert created from 2.0402 material the surface quality Ray was $0.41 \mu \mathrm{m}$ (Rz was $2.86 \mu \mathrm{m})$. While comparing the qualities of surface of the insert and the surface quality $\mathrm{Ra}$ of the product the difference of $86 \%$ (Rz was $122 \%$ ) was found. From these results, it is evident that the copying of the roughness of the surface is dependent on the insert material and its thermal conductivity.

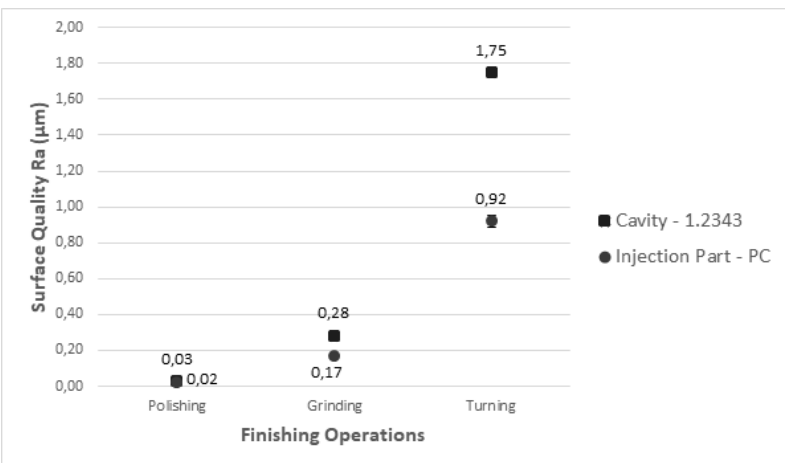

Fig. 6 Surface Quality Ra vs. Finishing Operations

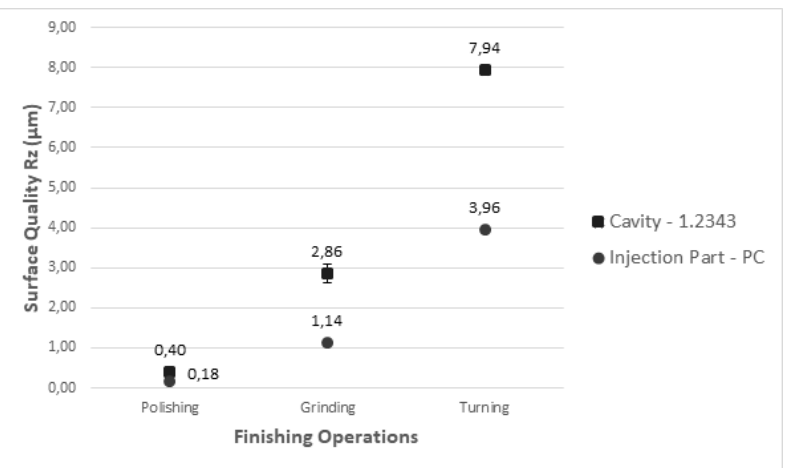

Fig. 7 Surface Quality Rz vs. Finishing Operations 
Figure 6 and Figure 7 shows the influence of the finishing operations (turning, grinding and polishing) on the surface quality. From Figure it is evident that the highest value of the surface quality $\mathrm{Ra}$ and $\mathrm{Rz}$ is at the shape insert, which is turned. The value of the surface quality $\mathrm{Ra}$ of the sample is $90 \%$ lower than the value of the surface quality of the insert ( $\mathrm{Rz}$ was $101 \%$ ). At grinded insert, the value is lower and the surface quality copies with the lower difference ( $\mathrm{Ra}$ was $65 \%$ and $\mathrm{Rz}$ was 151 $\%)$. At polished shape insert the value of the surface quality $\mathrm{Ra} 0.03 \mu \mathrm{m}(\mathrm{Rz} 0.4 \mu \mathrm{m})$ and copies to polymeric samples almost identical. The $\mathrm{Ra}$ value of the sample is $0.02 \mu \mathrm{m}$ abd Rz value of the sample was $0.18 \mu \mathrm{m}$.

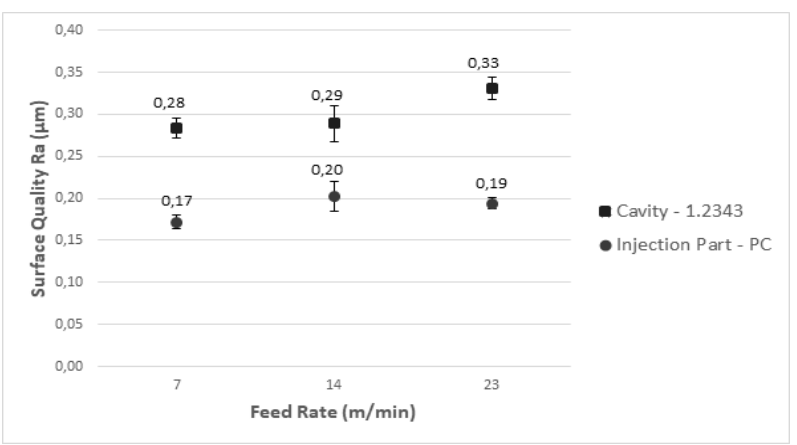

Fig. 8 Surface Quality Ra vs. Feed Rate

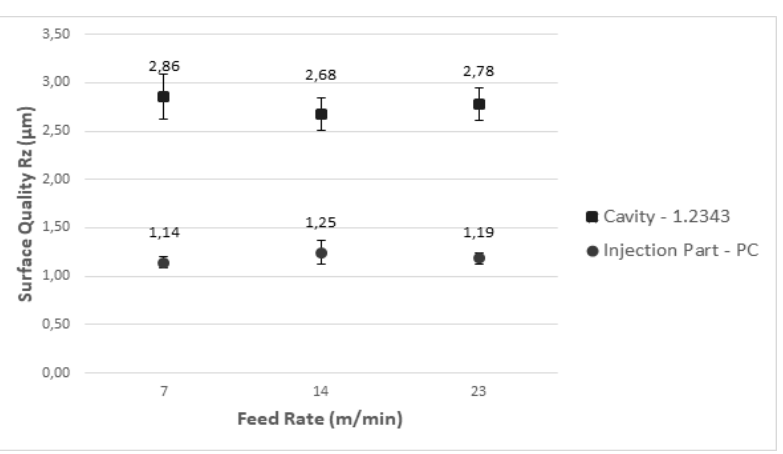

Fig. 9 Surface Quality Rz vs. Feed Rate

It is possible to find out at the results of the grinded surface at the feed rate $(7 \mathrm{~m} / \mathrm{min}, 14 \mathrm{~m} / \mathrm{min}$ and $23 \mathrm{~m} / \mathrm{min})$ that from Figure 8 and Figure 9 is evident that with increasing feed rate the value of surface quality $\mathrm{Ra}$ and $\mathrm{Rz}$ increases. The highest value of the quality $\mathrm{Ra}$ is at the highest feed rate $23 \mathrm{~m} / \mathrm{min}$. After comparison of the surface quality of the insert and the injection moulded sample it is evident that the surface quality of the sample has lower value of $\mathrm{Ra}$ than the shape insert. The lowest difference between $\mathrm{Ra}$ of the insert and $\mathrm{Ra}$ of the sample is during grinding of the insert at feed rate $7 \mathrm{~m} / \mathrm{min}$ where the sample has $65 \%$ lower value of $\mathrm{Ra}$ than the insert with the highest difference between the insert and the sample at the feed rate $23 \mathrm{~m} / \mathrm{min}$, where the sample has $74 \%$ lower Ra.

\section{Conclusions}

The aim of this study was to investigate the influence of the quality of the injection moulded mould on the surface quality of the polymeric product. Used materials of the injection mould were 1.2343, 1.3505 and 2.0402 and as a polymeric material, $\mathrm{PC}$ was used. From the results it is evident that used material of the injection mould has a significant influence on the surface quality of the final polymeric product. The surface of the mould copied with the smallest difference the surface of the product at material 1.3505 where the difference was $52 \%$, while the worst copyable is the surface of material 2.0402, the difference is $86 \%$.

During using of various finishing operations (turning, grinding and polishing) it is clear that polishing copies the surface almost identical, while at grinding and turning higher differences were observed at the surface quality of the mould and the product. This difference is approximately $65 \%$ at grinding and $90 \%$ at turning.

During using of various velocities of grinding it is evident that the most suitable velocity is $14 \mathrm{~m} / \mathrm{min}$ when the surface quality of the mould was $0.29 \mu \mathrm{m}$ and this surface was copied on the surface of the plastic product with the value of $0.2 \mu \mathrm{m}$. The difference in the surface quality of the mould at the product was $45 \%$.

The results clearly indicate that the surface quality of the mould cavity positively influences the surface quality of the final product, i.e., higher surface quality of the mould cavity resulted in higher surface quality of the final product.

This research would be appropriate to extend about more polymeric materials or tool materials and to focus on the rheological properties of the polymeric material or the melt flow index.

\section{Acknowledgement}

This work was supported by the European Regional Development Fund under the project CEBIA-Tech Instrumentation No. CZ.1.05/2.1.00/19.0376 and by the Ministry of Education, Youth and Sports of the Czech Republic within the National Sustainability Program project no. LO1303 (MSMT-7778/2014). Moreover, it was supported by the Internal Grant Agency of TBU in Zlin: no. IGA/FT/2019/002.

\section{References}

[1] WANG, J., XU, Y., ZHANG, W., MOUMNI, Z. (2016). A damage-based elastic-viscoplastic constitutive model for amorphous glassy polycarbonate polymers. In: Materials and Design, Vol. 97, pp. 519-531.

[2] XU, Y., HUAN, L., GAO, T., ZHANG, W. (2015). Predicting the low-velocity impact behavior of polycarbonate: Influence of thermal history during injection molding. In: International Journal of Impact Engineering, pp. 265-273.

[3] GRIFFITHS, C.A., DIMOV, S.S., BROUSSEAU, E.B., HOYLE, R.T. (2007). The effects of tool surface quality in micro-injection moulding. In: Journal of Materials Processing Technology, Vol. 189, pp. 418-427.

[4] OZCELIK, B., OZBAY, A., DEMIRBAS, E. (2010). Influence of injection parameters and 
mold materials on mechanical properties of ABS in plastic injection molding. In: International Communications in Heat and Mass Transfer, Vol. 37, pp. 1359-1365.

[5] SAKO, T., ITO, A., YAMAGUCHI, M. (2017). Surface segregation during injection molding of polycarbonate/poly(methyl methacrylate) blend. In: Journal of Polymer Research, Vol. 24.

[6] OVSIK, M., SENKERIK, V., MANAS, D., STANEK, M. (2016). The behaviour of cross-linking filled PBT measured by nano-hardness. In: MM Science Journal, pp. 1110-1113.

[7] EPERJESI, S., MATVIJA, M., BARTOSOVA, M., FECKO, D., PRIBULOVA, A. (2017). Effect of Heat Treatment Conditions on Micro Structure of Cast Iron. In: Manufacturing Technology, Vol. 17 , pp. 29-33.
[8] MULlER, M. (2017). Effects of Aluminium Microparticles and Surface Treatment of $\mathrm{AlCu} 4 \mathrm{Mg}$ on Mechanical Properties of Adhesive Bond Strength. In: Manufacturing Technology, Vol. 17, pp. 66-71.

[9] KUBISOVA, M., PATA, V., SYKOROVA, L., KNEDLOVA, J. (2017). Influence of laser beam on polymer materiál. In: Manufacturing Technology, Vol. 17, No. 5, pp. 742-746.

[10] MANAS, D., OVSIK, M., MIZERA, A., MANAS, M., HYLOVA, L., BEDNARIK, M., STANEK, M. (2018). The effect of irradiation on mechanical and thermal properties of selected types of polymers, In: Polymers, Vol. 10, No. 2, pp. 158. 